\title{
RHEOLOGICAL STRAINS IN CONCRETE MODIFIED WITH STEEL FIBRE REINFORCEMENT
}

\author{
Czesław BYWALSKI, Mieczysław KAMIŃSKI \\ Institute of Building Engineering, Wrocław University of Technology, Plac Grunwaldzki 11, \\ 50-377 Wroctaw, Poland
}

Received 22 Mar. 2013; accepted 2 May 2013

\begin{abstract}
This paper discusses the rheological properties of normal (ordinary) strength concrete. The results of tests aimed at determining the creep strains and shrinkage strains in normal strength concretes modified with steel fibre reinforcement are presented. The tests were divided into three groups. Steel fibre reinforced concretes (SFRCs) with a different composition were studied in each of the groups. Hook steel fibres, $50-\mathrm{mm}$ long and $0.8 \mathrm{~mm}$ in diameter, were used in the tested SFRCs. The latter had an average compressive strength of 35.17-59.18 MPa and a steel fibre content of $0,25,35,50$ and $65 \mathrm{~kg}$ per $1 \mathrm{~m}^{3}$ of the concrete mixture respectively. Functional dependences for the increase in shrinkage and creep strains over time are given. The problem of the effect of aggregate grading on creep strains is addressed. Conclusions concerning the rheological deformability of steel fibre reinforced concrete are drawn.
\end{abstract}

Keywords: steel fibre reinforced concrete (SFRC); rheological properties; creep; shrinkage.

Reference to this paper should be made as follows: Bywalski, C.; Kamiński, M. 2013. Rheological strains in concrete modified with steel fibre reinforcement, Journal of Civil Engineering and Management 19(5): 656-664. http://dx.doi.org/10.3846/13923730.2013.803497.

\section{Introduction}

Steel fibre reinforced concrete (SFRC) has been around already for a few decades (Swamy, Mangat 1974; Batson 1976). Initially, concrete would be usually modified with a small amount of long fibres. As the concrete technology developed, shorter fibres in larger volumetric amounts as well as mixtures of short and long fibres began to be used (Caggiano et al. 2012). Also increasingly higher concrete strengths could be achieved whereby high performance concrete (HPC) and ultra-high performance concrete (UHPC) could be produced. But as plain concrete became stronger, its brittleness increased. Therefore, steel fibres, significantly improving the plastic properties of plain concrete, were introduced into its composition. In this way, high performance steel fibre reinforced concrete (HPSFRC) and ultra-high performance steel fibre reinforced concrete (UHPSFRC) were obtained. The composites differ quantitatively and, in some cases, also qualitatively in their material characteristics.

HPSFRC and UHPSFRC are used for, e.g. bridges and tall buildings. SFRC is mainly used for industrial floors. It should be noted, however, that it is a different material - usually with lower strength parameters and long steel fibres.

There is an extensive literature on the mechanical properties of fibre reinforced concretes. But the literature on their rheological properties, particularly creep, is rather scanty. This paper presents the results of the authors' research on the creep strains and shrinkage of plain concretes modified with steel fibre reinforcement (12 series of composites). The results represent a significant contribution to the one reported in the literature so far. Moreover, functional dependences for the increase in shrinkage and creep strains over time are given and the problem of the effect of aggregate grading on creep strains is addressed. Conclusions concerning the rheological deformability of steel fibre reinforced concrete are drawn.

\section{Literature review}

The mechanical properties of steel fibre reinforced concrete are well known. Numerous researchers have found that the beneficial effect of a steel fibre addition on the mechanical properties of the concrete always becomes apparent under tension (Holschemacher et al. 
2010). Nevertheless, steel fibre reinforced concretes continue to be studied (Shah, Ribakov 2011; Hassan et al. 2012). For example, the influence of the slenderness and content of the steel fibres on the mechanical properties of the composite is investigated (Yazici et al. 2007).

As regards the rheological properties (creep and shrinkage) of SFRCs, it appears that the research findings have been rather limited (Ezeldin, Shiah 1995), especially in the case of creep (Velasco et al. 2008). The effect of the steel fibre addition on the magnitude of shrinkage strains has been relatively well identified. Most researchers have confirmed the positive contribution of the steel fibre addition towards the reduction of shrinkages strains, but research into this is still continued. Also the effect of different factors on shrinkage strains in concrete without steel fibres is studied. The results reported by Asamato et al. (2008a, b) and Mihashi et al. (2008) confirm that shrinkage strains depend on the E-modulus of the aggregate and they are smaller, the higher the Emodulus. Shrinkage strains are affected not only by the composition of the concrete mixture, but also by its consistence (Kockal, Turker 2008) - the shrinkage of semiliquid concrete is smaller than that of liquid concrete. Also the environmental conditions have a bearing on shrinkage strains (Min et al. 2008). The influence of pore structure on mechanical and rheological properties of concretes was also investigated (Gorzelańczyk, Hoła 2011). Current research supplies many data useful for creating or modifying material models of steel fibre reinforced concrete (Luccioni et al. 2012) and plain concrete (Gribniak et al. 2008).

No general conclusions, however, can be drawn from the relatively modest research results on creep strains in steel fibre reinforced concrete. Some of the results indicate that creep strains decrease with the increasing amount of the added steel fibres (Chern, Young 1989), while others suggest that the strains increase (Velasco et al. 2008). Balaguru and Ramakrishnan (1988) and Grzybowski and Shah (1990) claim that a small steel fibre content (below $1 \%$ by volume) practically has no effect on the rheological strains of the SFRC.

The magnitude of creep strains, to a significant degree, depends on the composition of plain concrete or steel fibre reinforced concrete, i.e. on the type and grading of the aggregate, the type of cement, the w/c ratio, etc. This is observed within the same grade of concrete. In some cases, the differences in the size of the strains amount to a few tens of per cent. Design standards, e.g. ENV 1992-1-1:2004 - Eurocode 2 (1992), take into account the type of cement in creep coefficient calculations, but they disregard, e.g. the type and grading of aggregate. In this context, one should note that creep strains in normal strength concrete are greater than in high performance concrete (Voo, Foster 2010) made using aggregate characterized by a higher E-modulus.

On the basis of the existing knowledge, it can be stated that it is possible to observe different values of shrinkage strains and creep strains within the same strength class of concrete based on concrete mixtures differing in only their w/c ratio. This is reflected in the partial coefficients, taking into account the influence of the w/c ratio on the above strains, used in the various methods of estimating rheological strains. The coefficients can be determined using the available nomograms (ENV 1992-1-1:2004 - Eurocode 2 1992). No such nomograms, however, have been developed for steel fibre reinforced concretes.

One needs to know creep strains, e.g. to estimate the deflections of SFRC beams (Bywalski, Kamiński 2011). The simplified methods of estimating the longterm deflections of SFRC beams are based on the creep coefficient which can be determined using various methods, quite often yielding significantly different values (Watanabe et al. 2008).

Creep strains are also needed to verify rheological models. One of such models was presented by Bažant (1995).

There are two main approaches to rheological problems. One of them consists in schematizing rheological phenomena by creating models composed of a few simple components while in the other approach, the phenomena are represented using the creep function. A survey of simple rheological concrete models was presented by Szechiński (2000). Simple models, such as the elasticity model, the viscosity model, the dry friction model, the Maxwell model, the Kelvin-Voight model and the viscoplasticity St. Venant model, are being modified and extended in order to correctly describe novel concrete composites. The conditions which a rheological model must meet should be determined on the basis of experimental results.

The strain of plain concrete and steel fibre reinforced concrete under stress can be generally divided into:

- Instantaneous (immediate) elastic strain $\varepsilon_{e l}$, caused by short-duration stress $\sigma$. This strain is not time-dependent and it disappears once the stress is removed;

- Strain caused by sustained permanent load, further referred to as creep strain $\varepsilon_{c}$, which over time asymptotically approaches a certain limit value;

- Shrinkage strain $\varepsilon_{s h}$, which is mainly determined by time.

After load relief (stress removal), creep strains are partly recoverable (then they are referred to as retarded elastic strains $\varepsilon_{c 2}$ ) and partly non-recoverable (referred to as plastic strains $\varepsilon_{c 1}$ ). 
(a)

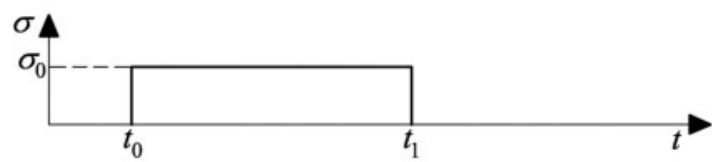

(b)

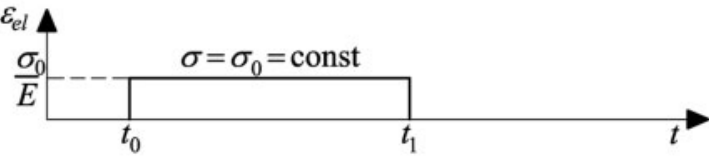

(c)

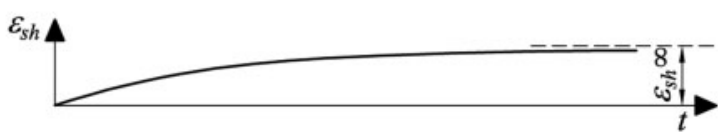

(d)

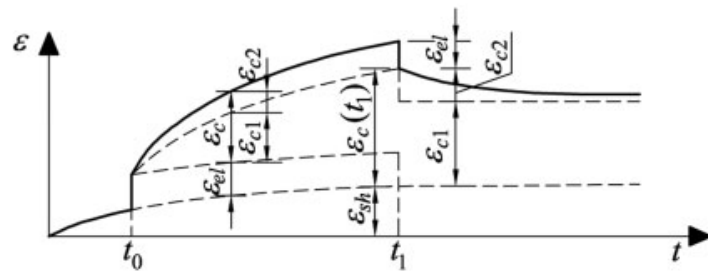

Fig. 1. Diagrams of elastic and rheological strains: (a) load versus time ( $t_{0}$ - loading instant, $t_{1}$ - relief instant); (b) elastic strain versus time; (c) shrinkage strain; (d) total strain

Fig. 1 schematically shows the shape of typical strains experimentally determined under permanent compressive load in time interval $<t_{0}, t_{1}>$. The total strain is the sum of the particular strains:

$$
\varepsilon=\varepsilon_{e l}+\varepsilon_{c}+\varepsilon_{s h}
$$

where: $\varepsilon$ - the total strain; $\varepsilon_{e l}$ - the instantaneous (immediate) elastic strain; $\varepsilon_{c}$ - the creep strain; $\varepsilon_{s h}-$ the shrinkage strain.

It appears from the diagrams that concrete subjected to loading, i.e. from instant $t=0$ to $t=t_{0}$, exhibits only shrinkage strains. When constant stress $\sigma$ is applied, the strains increase until unloading instant $t_{1}$. After the unloading of the plain concrete or the steel fibre reinforced concrete, recoverable elastic strain occurs, this is followed by (recoverable) retarded elastic strain. The remaining strain consists of nonrecoverable plastic strain and shrinkage strain.

The next sections of this paper presents, among other things, the results of creep tests carried out on steel fibre reinforced concretes characterized by medium compressive strength (ranging from 35.17 to $59.18 \mathrm{MPa}$ ) and a fibre content of $0,25,35,50$ and $65 \mathrm{~kg}$ in $1 \mathrm{~m}^{3}$ of the concrete mixture, respectively.

\section{Description of tests}

The tests were carried out in three groups, each comprising 4 SFRC series (12 series in total). In each of the groups, the first series represented reference concrete and the other three - steel fibre reinforced concrete. Steel fibres hooked at their ends, $50-\mathrm{mm}$ long and $0.8 \mathrm{~mm}$ in diameter, were used. The composition of the concrete mixtures is shown in Tables 1, 2 and 3.
Table 1. Concrete mixture composition - group I

\begin{tabular}{|c|c|c|c|c|c|}
\hline \multirow[b]{2}{*}{ Materials } & & \multicolumn{4}{|c|}{ Series } \\
\hline & & $\mathrm{A} / \mathrm{I}$ & $\mathrm{B} / \mathrm{I}$ & $\mathrm{C} / \mathrm{I}$ & $\mathrm{D} / \mathrm{I}$ \\
\hline Steel fibres & $\mathrm{kg} / \mathrm{m}^{3}$ & 35 & 50 & 65 & 0 \\
\hline Superplasticizer & $\mathrm{kg} / \mathrm{m}^{3}$ & 5.39 & 5.88 & 6.38 & 5.12 \\
\hline Cement & $\mathrm{kg} / \mathrm{m}^{3}$ & \multicolumn{4}{|c|}{420} \\
\hline $\begin{array}{l}\text { CEM I 42,5 R } \\
\text { w/c ratio }\end{array}$ & & \multicolumn{4}{|c|}{0.38} \\
\hline River sand $0-2 \mathrm{~mm}$ & $\mathrm{~kg} / \mathrm{m}^{3}$ & \multicolumn{4}{|c|}{626} \\
\hline Gravel 2-8 mm & $\mathrm{kg} / \mathrm{m}^{3}$ & \multicolumn{4}{|c|}{702} \\
\hline Gravel 8-16 mm & $\mathrm{kg} / \mathrm{m}^{3}$ & \multicolumn{4}{|c|}{571} \\
\hline
\end{tabular}

Table 2. Concrete mixture composition - group II

\begin{tabular}{llcccc}
\hline & & \multicolumn{4}{c}{ Series } \\
\cline { 3 - 6 } Materials & & $\mathrm{A} / \mathrm{II}$ & $\mathrm{B} / \mathrm{II}$ & $\mathrm{C} / \mathrm{II}$ & $\mathrm{D} / \mathrm{II}$ \\
\hline Steel fibres & $\mathrm{kg} / \mathrm{m}^{3}$ & 25 & 35 & 50 & 0 \\
Superplasticizer & $\mathrm{kg} / \mathrm{m}^{3}$ & 1.58 & 1.97 & 2.51 & 0.47 \\
Cement & $\mathrm{kg} / \mathrm{m}^{3}$ & & 363 & \\
CEM I 32,5 R & & & & \\
w/c ratio & & & 0.46 & \\
River sand 0-2 mm & $\mathrm{kg} / \mathrm{m}^{3}$ & & 663 & \\
Gravel 2-8 mm & $\mathrm{kg} / \mathrm{m}^{3}$ & & 568 & \\
Gravel 8-16 mm & $\mathrm{kg} / \mathrm{m}^{3}$ & \multicolumn{3}{c}{663} \\
\hline
\end{tabular}

The specimens to be tested were vibrated on a vibrating table for about one minute. After three days, the moulds were removed and the specimens were stored in constant temperature-humidity conditions (air temperature $20 \pm 2{ }^{\circ} \mathrm{C}$ and relative air humidity below $95 \%$ ) until testing.

The procedure described in RILEM (1983) was used to determine creep strains. Compression creep strains were determined using cylindrical specimens, $113 \mathrm{~mm}$ in diameter and $350 \mathrm{~mm}$ high $(\mathrm{h} / \mathrm{d} \approx 3)$, after 28 days since concreting. The specimens were placed in creep-testing machines and loaded to the level of one third of the SFRC composite average strength (Table 4).

Table 3. Concrete mixture composition - group III

\begin{tabular}{lccccc}
\hline & & \multicolumn{4}{c}{ Series } \\
\cline { 3 - 6 } Materials & & $\mathrm{A} / \mathrm{III}$ & $\mathrm{B} / \mathrm{III}$ & $\mathrm{C} / \mathrm{III}$ & $\mathrm{D} / \mathrm{III}$ \\
\hline Steel fibres & $\mathrm{kg} / \mathrm{m}^{3}$ & 25 & 35 & 50 & 0 \\
Superplasticizer & $\mathrm{kg} / \mathrm{m}^{3}$ & 1.85 & 2.43 & 3.03 & 0.65 \\
Cement & $\mathrm{kg} / \mathrm{m}^{3}$ & & 363 & \\
CEM II BM 32,5 R & & & & \\
w/c ratio & & & 0.46 & \\
River sand 0-2 mm & $\mathrm{kg} / \mathrm{m}^{3}$ & & 663 & \\
Gravel 2-8 mm & $\mathrm{kg} / \mathrm{m}^{3}$ & & 568 & \\
Gravel 8-16 mm & $\mathrm{kg} / \mathrm{m}^{3}$ & \multicolumn{5}{c}{663} \\
\hline
\end{tabular}


Table 4. Mean compressive strength $f_{c m}$ of tested SFRCs

\begin{tabular}{llcc}
\hline Group & Series & $\begin{array}{c}\text { Compressive strength } \\
f_{c m}, \mathrm{MPa}\end{array}$ & $\begin{array}{c}\text { Standard deviation } \\
s, \mathrm{MPa}\end{array}$ \\
\hline I & $\mathrm{A} / \mathrm{I}$ & 56.74 & 1.34 \\
& $\mathrm{~B} / \mathrm{I}$ & 57.17 & 0.38 \\
& $\mathrm{C} / \mathrm{I}$ & 59.18 & 1.54 \\
& $\mathrm{D} / \mathrm{I}$ & 55.48 & 0.67 \\
$\mathrm{II}$ & $\mathrm{A} / \mathrm{II}$ & 47.11 & 1.61 \\
& $\mathrm{~B} / \mathrm{II}$ & 40.37 & 1.92 \\
& $\mathrm{C} / \mathrm{II}$ & 42.10 & 0.56 \\
& $\mathrm{D} / \mathrm{II}$ & 34.74 & 1.49 \\
$\mathrm{III}$ & $\mathrm{A} / \mathrm{III}$ & 39.70 & 1.20 \\
& $\mathrm{~B} / \mathrm{III}$ & 35.17 & 1.58 \\
& $\mathrm{C} / \mathrm{III}$ & 35.87 & 1.63 \\
& D/III & 40.53 & 1.42 \\
\hline
\end{tabular}

Six cylindrical specimens, $113 \mathrm{~mm}$ in diameter and $350-\mathrm{mm}$ high, were used to determine compressive strength. The creep-testing machine design guaranteed load axiality, which had been checked by measuring strains under a load corresponding to $20 \%$ of the specimen's average compression strength. The compressive load was applied in three steps: $1 / 3$, $2 / 3$ and the full target load, and at the same time, readings of the strains in the particular loading steps and 5 minutes after loading were taken. The specimens would be fully loaded in time not exceeding 10 minutes. Creep strain readings were taken at proper time intervals, i.e. every day in the first week, at least once a week for the period of three months and at least once a month in the remaining period. Shrinkage strains were separated from creep strains in order to make possible a detailed analysis of the rheological properties of the tested SFRCs. For this purpose, the shrinkage strains of cylindrical specimens, $113 \mathrm{~mm}$ in diameter and $350 \mathrm{~mm}$ high, were recorded in parallel

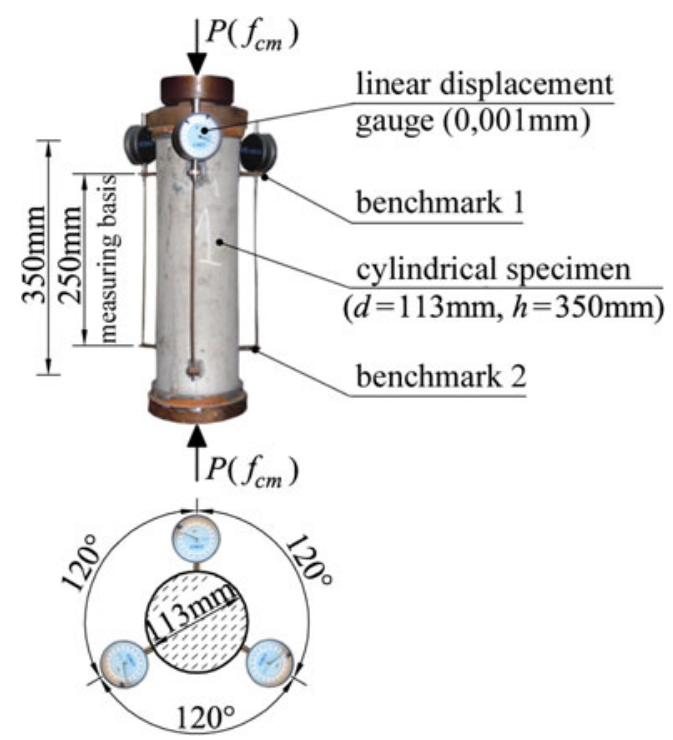

Fig. 2. Schematic showing specimen armed for creep strain determination

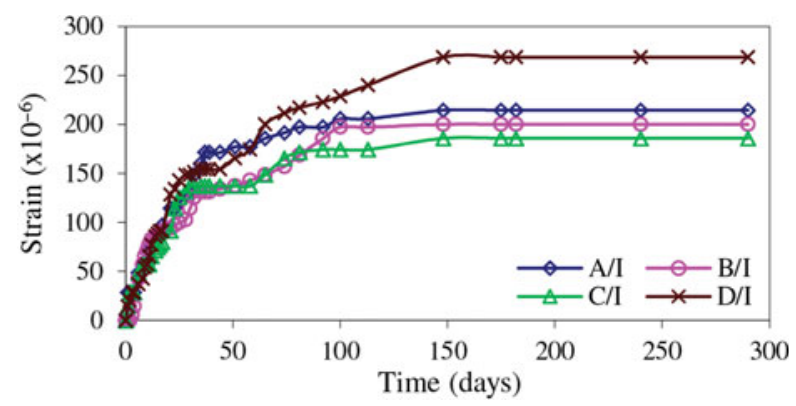

Fig. 3. Shrinkage strains in SFRCs and in plain concrete group I

with creep strains. Both kinds of strains were determined using 3 specimens in each series.

Shrinkage and creep strains were measured by dial gauges with a measuring basis of $0.001 \mathrm{~mm}$. In the case of creep strains, the displacement of benchmarks, stuck on the specimens at a basal distance of $250 \mathrm{~mm}$, was measured. The benchmarks were spaced at every $120^{\circ}$ on the specimen circumference. A schematic of the specimen armed for creep strain determination is shown in Figure 2. In the case of shrinkage strain determination, the measuring basis was equal to the specimen height. Strain and shrinkage readings were taken concurrently with creep strain readings.

The tests were carried out in constant temperature-humidity conditions, i.e. at an air temperature of $20 \pm 2{ }^{\circ} \mathrm{C}$ and an air relative humidity of $60 \pm 4 \%$.

\section{Test results and their analysis}

Figures 3, 4 and 5 show comprehensive diagrams of total strains and selected components of the strains for the group I SFRCs

Figure 3 shows a significant contribution of the fibres towards the ultimate shrinkage strains, amounting to as much as $30 \%$ (series $\mathrm{C} / \mathrm{I}$ ) relative to the fibreless concrete $(\mathrm{D} / \mathrm{I})$. This contribution is larger if the steel fibre content in the unit volume of the concrete is higher and vice versa. The tests showed that for the adopted amounts of steel fibres, their presence does not contribute towards any reduction in ultimate creep strains in the SFRC (Fig. 4). In the case of series C/I (the fibre addition amounting to

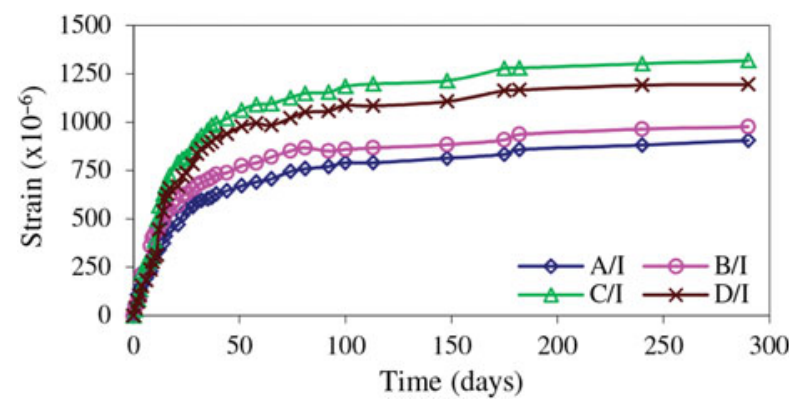

Fig. 4. Creep strains in SFRCs and in plain concrete group I 


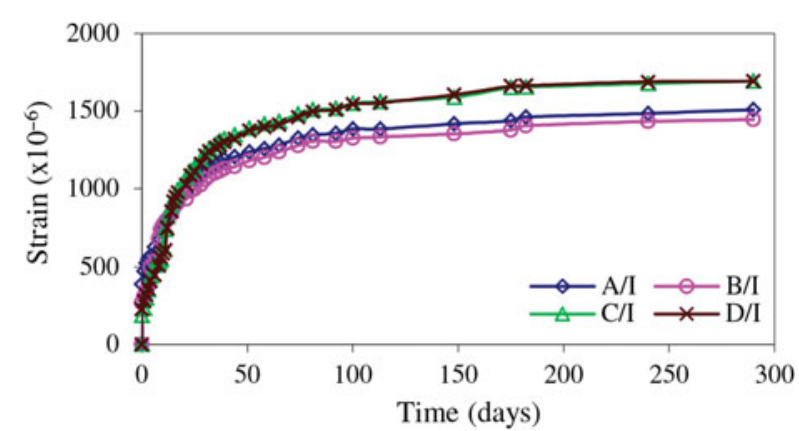

Fig. 5. Immediate and rheological total strains in SFRCs and in plain concrete - group I

$65 \mathrm{~kg} / \mathrm{m}^{3}$ ), the creep strains in the SFRC were even higher than the ones in the series $\mathrm{D} / \mathrm{I}$ concrete. Therefore, the hypothesis that the concrete matrix (more precisely, its quality) determines the magnitude of creep strains was put forward. The quality of the concrete matrix is affected by, among other things, the concrete mixture compaction and the aggregate grading curve. However, it was necessary to carry out more tests in order to generalize the conclusions. The results of the tests are presented later in this paper.

An analysis of the total (immediate and rheological) strain curves shown in Figure 5 indicates that the effect of the steel fibre addition on the strains in the concrete subjected to compression is negligibly small. Immediate strains are understood to be the strains observed immediately after the application of compressive stress. Rheological strains are the (creep and shrinkage) strains observed over time.

Figures 6, 7 and 8 show comprehensive diagrams of total strains and selected components of the strains for the group II SFRCs

Considering the test results obtained from group I, and also in group II, one could expect a small reduction in shrinkage and creep strains with increasing steel fibre content. But the curves in Figure 6 do not confirm such expectations. However, it became apparent that the strains for series $\mathrm{A} / \mathrm{II}$ and $\mathrm{D} / \mathrm{II}$ as well as series $\mathrm{B} / \mathrm{II}$ and $\mathrm{C} / \mathrm{II}$ were quantitatively similar, but at the same time, the above groups of series significantly differed in their strain values.

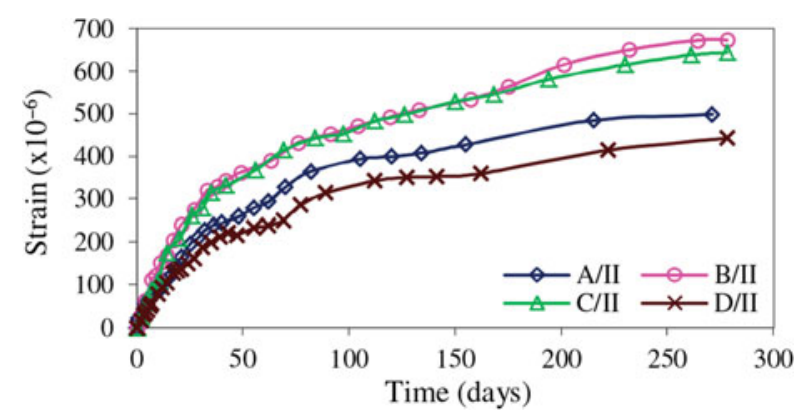

Fig. 6. Shrinkage strains in SFRCs and in plain concrete group II

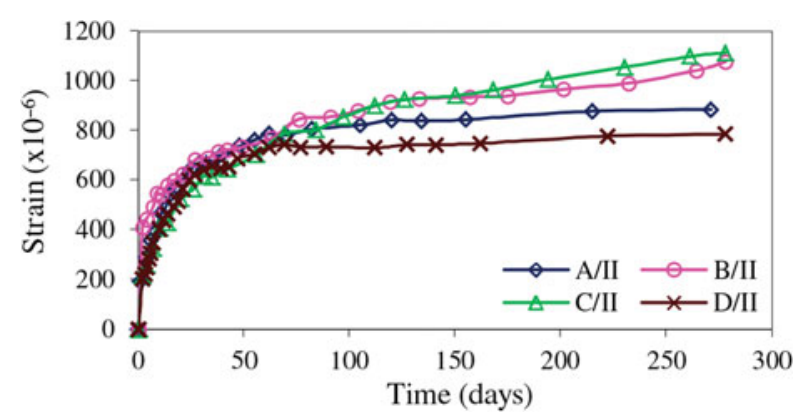

Fig. 7. Creep strains in SFRCs and in plain concrete group II

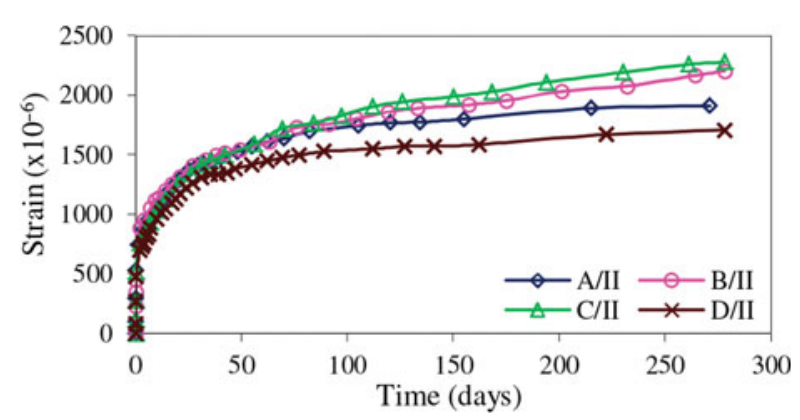

Fig. 8. Immediate and rheological total strains in SFRCs and in plain concrete - group II

The main cause was found to be the unintended slightly different grading of the aggregate used. The 8 $16 \mathrm{~mm}$ gravel in the case of series B/II and C/II was characterized by higher fine particle content. In order to determine the differences between the particle size fractions of the 8-16 $\mathrm{mm}$ gravel, used for the particular series, the gravel was additionally sieved using a sieve aperture of $12 \mathrm{~mm}$. In this way, two subfractions, $8-12 \mathrm{~mm}$ and $12-16 \mathrm{~mm}$, were obtained. The aggregate grading curve for the $8-16-\mathrm{mm}$ fraction is shown in Figure 9. One can see that the content of aggregate particles passing through the sieve with an aperture of $12 \mathrm{~mm}$ is higher for series B/II and C/II. Within the 12-16 $\mathrm{mm}$ aggregate fraction, the share of the $8-12$ subfraction amounted to $43 \%$ and $86 \%$ for series $\mathrm{A} / \mathrm{II}$ and $\mathrm{D} / \mathrm{II}$ and series $\mathrm{B} / \mathrm{II}$ and $\mathrm{C} / \mathrm{II}$, respectively.

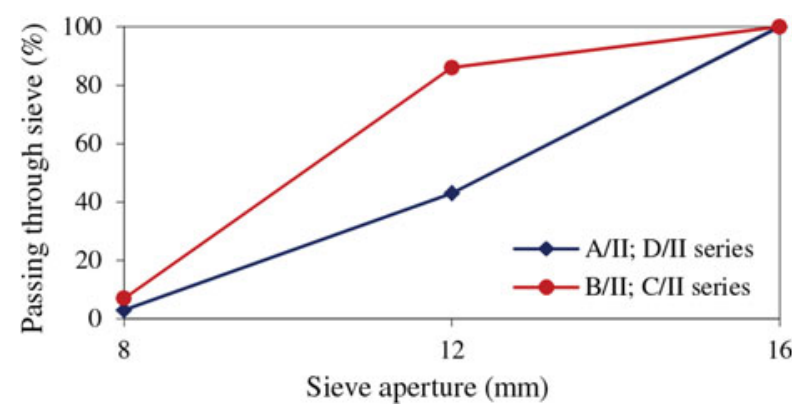

Fig. 9. Aggregate particle size distribution for $8-16 \mathrm{~mm}$ fraction group 


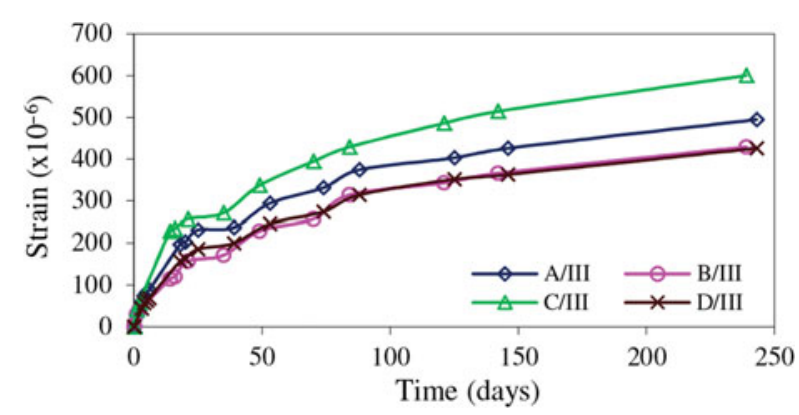

Fig. 10. Shrinkage strains in SFRCs and in plain concrete group III

A comparison of the curves in Figure 7 shows that within a single concrete strength class, creep strains may significantly differ depending on the aggregate grading - higher fine fraction content contributes towards an increase in creep strains. If one compares the curves shown in Figure 6, it becomes apparent that the shrinkage strains in the concrete based on the finer aggregate are greater than the ones in the concrete based on the coarser aggregate. As a result, the total strains for the group of series $\mathrm{B} / \mathrm{II}$ and $\mathrm{C} / \mathrm{II}$ are greater than for the group of series $\mathrm{A} / \mathrm{II}$ and D/II (Fig. 8).

On the basis of the findings made by Balaguru and Ramakrishnan (1988) and Grzybowski and Shah (1990) and the results of test group I, the hypothesis that creep strains in the SFRCs for the test plan steel fibre content of below $65 \mathrm{~kg} / \mathrm{m}^{3}$ do not depend on the steel fibre content in the concrete unit volume was put forward. The results of test group II confirmed this hypothesis, but they required a commentary because of the unintended differences in the aggregate grading. Therefore, in order to dispel any doubts as to the validity of the formulated thesis, creep strains were determined by tests carried out as part of group III in which the aggregate grading was identical for all the series. The obtained results are shown in Figures 10, 11 and 12. They confirm the formulated hypothesis. In Figure 10, one can see greater shrinkage strains in the SFRC than in the concrete without steel fibres. In Figure 11, the creep strains in the SFRCs with the higher fibre content (series $\mathrm{B} / \mathrm{III}$ and $\mathrm{C} / \mathrm{III}$ ) are greater

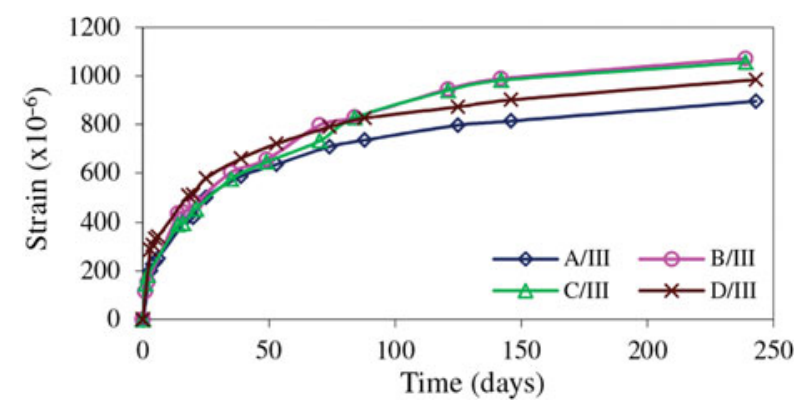

Fig. 11. Creep strains in SFRCs and in plain concrete group III

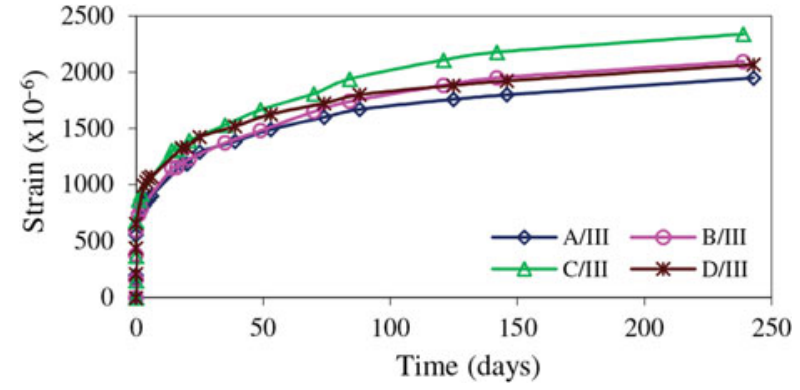

Fig. 12. Immediate and rheological total strains in SFRCs and in plain concrete - group III

than the creep strains in the plain concrete (series D/ III) and the latter strains are greater than the ones in the SFRC with the lowest fibre content (series A/III). This means that the addition of steel fibres has no significant effect on the rheological strain values in steel fibre reinforced concrete. The quality of the concrete matrix is more important in this regard. Neither a constant trend nor a significant effect of the fibre addition on the total strains in the SFRC was observed (Fig. 12).

\section{Empirical model}

The experimentally determined shrinkage and creep strains in the SFRCs were used to select deterministic functions and their parameters describing the increase in the separated shrinkage strains and creep strains over time. For this purpose, an empirical model was built using the generalized weighted least squares method (Gruszczyński, Podgórska 2004). The model is described by this relation:

$$
\varepsilon(t)=e^{A}\left(1-e^{-B t}\right) \xi_{t},
$$

where: $\xi_{t}-$ a random perturbation, $A$ and $B$ - model parameters.

Using the equivalent notation

$$
E_{t}=\ln \left(\varepsilon_{t}\right)
$$

one gets

$$
E_{t}=A+\ln \left(1-e^{-B t}\right)+e_{t},
$$

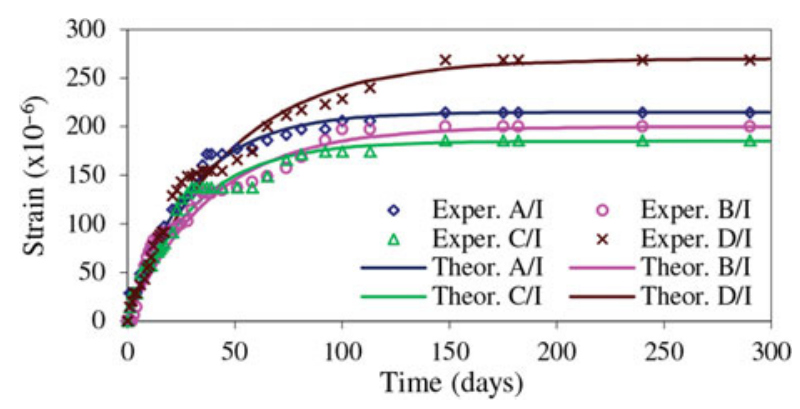

Fig. 13. Deterministic functions describing increase in shrinkage strains over time against experimental data group I 


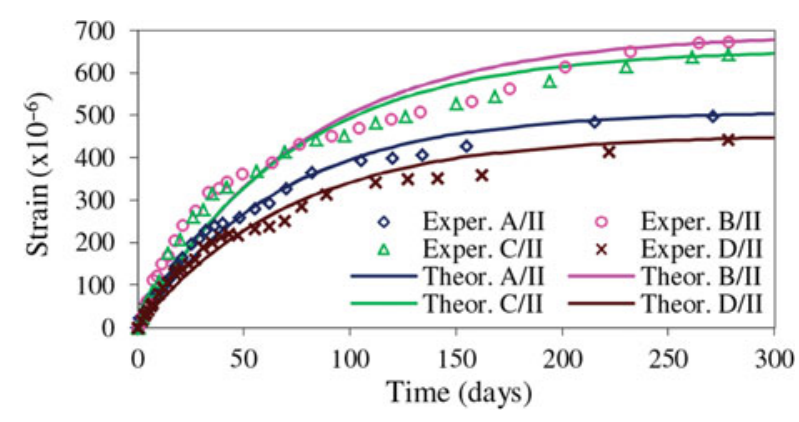

Fig. 14. Deterministic functions describing increase in shrinkage strains over time against experimental data group II

where

$$
e_{t}=\ln \left(\xi_{t}\right)
$$

The generalized weighted least squares method comes down to the minimization of loss function (6). The estimators are numerically calculated:

$$
\Gamma_{p}(A, B)=\sum_{t=1}^{n}\left(Y_{t}-A-\ln \left(1-e^{-B t}\right)\right)^{2} e^{2 p B t},
$$

where: $\mathrm{A} \in \mathbf{R}$ and $\mathrm{B}>0 ; p-\mathrm{a}$ specified positive number (a parameter).

Figures 13, 14 and 15 show the selected deterministic functions describing the increase in shrinkage strains over time against the experimental data for the SFRCs investigated in groups I, II and III.

The increase in shrinkage strains over time for the SFRCs tested in group I is approximated by the expressions: (7) - series A/I, (8) - series B/I, (9) series C/I and (10) - series D/I. In all the relations presented further in this paper, $\varepsilon(t)$ stands for an increase in appropriate strains over time $t$ :

$$
\begin{aligned}
& \varepsilon(t)=0.000215\left(1-e^{-0.034 t}\right) ; \\
& \varepsilon(t)=0.000201\left(1-e^{-0.026 t}\right) ; \\
& \varepsilon(t)=0.000185\left(1-e^{-0.033 t}\right) ; \\
& \varepsilon(t)=0.000270\left(1-e^{-0.022 t}\right) .
\end{aligned}
$$

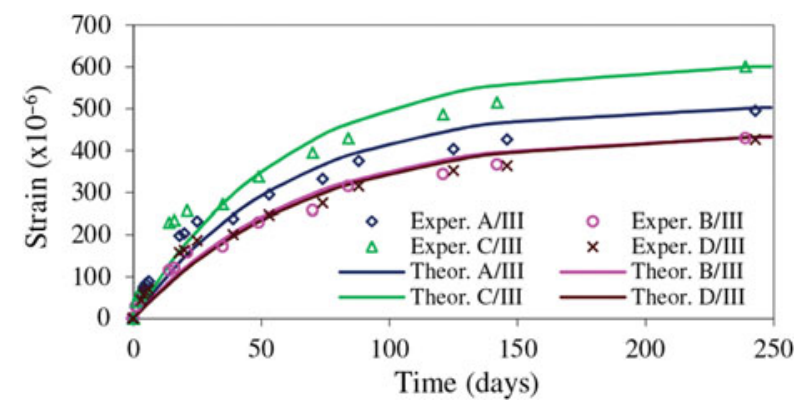

Fig. 15. Deterministic functions describing increase in shrinkage strains over time against experimental data group III

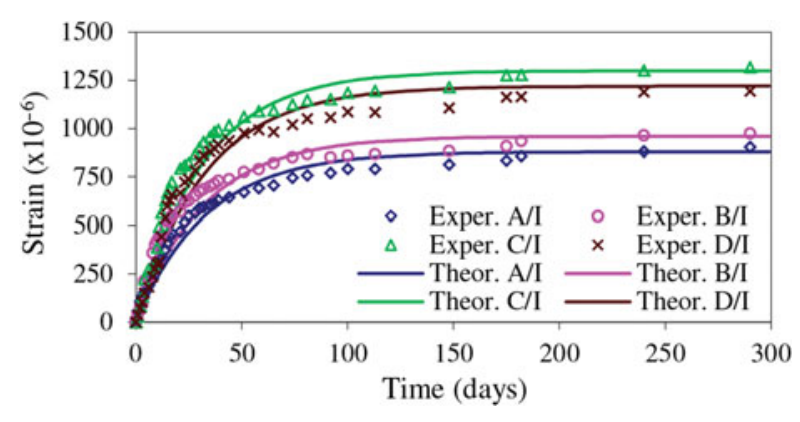

Fig. 16. Deterministic functions describing increase in creep strains over time against experimental data - group I

The increase in shrinkage strains over time for the SFRCs tested in group II is approximated by the expressions: (11) - series A/II, (12) - series B/II, (13) series $\mathrm{C} / \mathrm{II}$ and (14) - series D/II:

$$
\begin{aligned}
& \varepsilon(t)=0.000511\left(1-e^{-0.015 t}\right) ; \\
& \varepsilon(t)=0.000693\left(1-e^{-0.013 t}\right) ; \\
& \varepsilon(t)=0.000656\left(1-e^{-0.014 t}\right) ; \\
& \varepsilon(t)=0.000455\left(1-e^{-0.013 t}\right),
\end{aligned}
$$

The increase in shrinkage strains over time for the SFRCs tested in group III is approximated by the expressions: (15) - series A/III, (16) - series B/III, (17) series C/III and (18) - series D/III:

$$
\begin{aligned}
& \varepsilon(t)=0.000510\left(1-e^{-0.017 t}\right) ; \\
& \varepsilon(t)=0.000440\left(1-e^{-0.016 t}\right) ; \\
& \varepsilon(t)=0.000611\left(1-e^{-0.017 t}\right) ; \\
& \varepsilon(t)=0.000444\left(1-e^{-0.015 t}\right),
\end{aligned}
$$

Figures 16, 17 and 18 show the deterministic functions describing the increase in creep strains over time against the experimental data for the SFRCs tested in respectively group I, II and III.

The increase in creep strains over time for the SFRCs tested in group $I$ is approximated by the relations: (19) - series A/I, (20) - series B/I, (21) series $\mathrm{C} / \mathrm{I}$ and $(22)-$ series $\mathrm{D} / \mathrm{I}$ :

$$
\varepsilon(t)=0.00088\left(1-e^{-0.030 t}\right),
$$

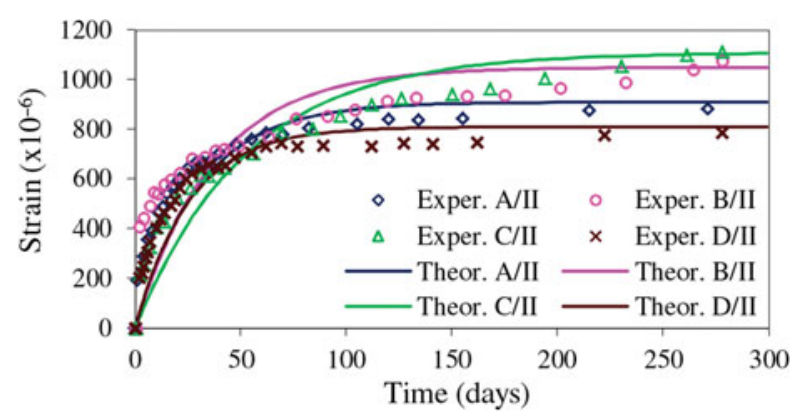

Fig. 17. Deterministic functions describing increase in creep strains over time against experimental data - group II 


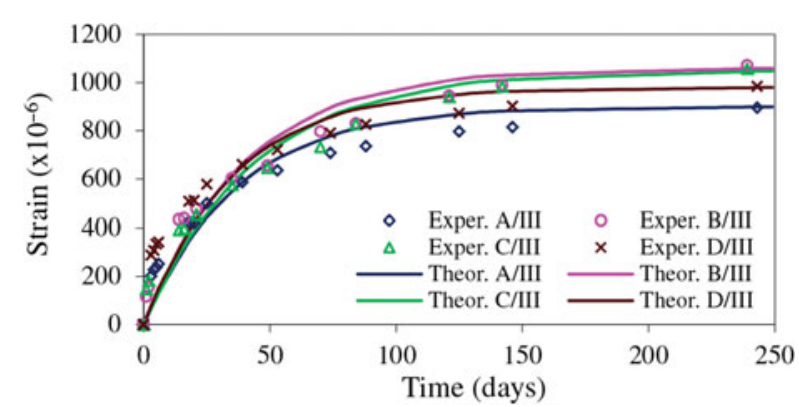

Fig. 18. Deterministic functions describing increase in creep strains over time - group III

$$
\begin{aligned}
& \varepsilon(t)=0.00096\left(1-e^{-0.031 t}\right) ; \\
& \varepsilon(t)=0.00131\left(1-e^{-0.031 t}\right) ; \\
& \varepsilon(t)=0.00121\left(1-e^{-0.030 t}\right) .
\end{aligned}
$$

The increase in creep strains over time for the SFRCs tested in group II is approximated by the relations: (23) - series A/II, (24) - series B/II, (25) series $\mathrm{C} / \mathrm{II}$ and (26) - series $\mathrm{D} / \mathrm{II}$ :

$$
\begin{aligned}
& \varepsilon(t)=0.00091\left(1-e^{-0.033 t}\right) ; \\
& \varepsilon(t)=0.00105\left(1-e^{-0.027 t}\right) ; \\
& \varepsilon(t)=0.00111\left(1-e^{-0.019 t}\right) ; \\
& \varepsilon(t)=0.00081\left(1-e^{-0.039 t}\right) .
\end{aligned}
$$

The increase in creep strains over time for the SFRCs tested in group III is approximated by the relations: (27) - series A/III, (28) - series B/III, (29) series C/III and (30) - series D/III:

$$
\begin{aligned}
& \varepsilon(t)=0.00090\left(1-e^{-0.027 t}\right), \\
& \varepsilon(t)=0.00106\left(1-e^{-0.025 t}\right), \\
& \varepsilon(t)=0.00105\left(1-e^{-0.023 t}\right), \\
& \varepsilon(t)=0.00098\left(1-e^{-0.028 t}\right) .
\end{aligned}
$$

\section{Conclusions}

The following conclusions can be drawn from the test results:

- The creep strains in the SFRCs with a steel fibre addition of below $65 \mathrm{~kg} / \mathrm{m}^{3}$ do not depend on the steel fibre content in the concrete unit volume.

- The above conclusion can be exploited in, among other things, assumptions for estimating the bending stiffness of structural members, using the creep strains for the concrete without steel fibres in the calculations.

- It is the concrete matrix, and more precisely its quality, which determines creep strain values. The quality of the concrete matrix is affected by, among other things, the degree of concrete mixture compaction and by the aggregate grading and type. Within one concrete strength class, creep strains may differ significantly depending on the aggregate grading - higher fine fraction content contributes towards an increase in creep strains.

- The experimental results have confirmed the data on the shrinkage strains in SFRCs, reported in the literature - in the case of SFRCs with fibre content below about $80 \mathrm{~kg}$ in $1 \mathrm{~m}^{3}$ of the concrete mixture, the fibre addition has no major effect on the creep strain values.

- The magnitude of shrinkage strains depends on, among other things, the kind of cement and the grading of the aggregate used in the concrete. The shrinkage strains of concrete based on finer aggregate are greater than the ones in concrete based on coarser aggregate.

\section{References}

Asamato, S.; Ishida, T.; Maekawa, K. 2008a. Investigations into volumetric stability of aggregates and shrinkage of concrete as a composite, Journal of Advanced Concrete Technology 6(1): 77-90.

http://dx.doi.org/10.3151/jact.6.77

Asamato, S.; Ishida, T.; Maekawa, K. 2008b. Multi-scale analysis of concrete shrinkage coupling with aggregate properties, in Proc. of the 8th International Conference on Creep, Shrinkage and Durability of Concrete and Concrete Structures, 30 September-2 October, 2008, Ise-Shima, Japan, vol. 1: 161-167.

Balaguru, P. N.; Ramakrishnan, V. 1988. Properties of fibre reinforced concrete: workability behaviour under long term loading and air-void characteristics, ACI Materials Journal 85(3): 189-196.

Batson, G. 1976. Steel fiber reinforced concrete, Materials Science and Engineering 25: 53-58. http://dx.doi.org/10.1016/0025-5416(76)90051-3

Bažant, Z. P. 1995. Creep and shrinkage predictions models for analysis and design of concrete structures - model B3, Materials and Structures 28(6): 357-365. http://dx.doi.org/10.1007/BF02473152

Bywalski, C. Z.; Kaminski, M. 2011. Estimation of the bending stiffness of rectangular reinforced concrete beams made of steel fibre reinforced concrete, Archives of Civil and Mechanical Engineering 11(3): 553-571. http://dx.doi.org/10.1016/S1644-9665(12)60101-0

Caggiano, A.; Cremona, M.; Faella, C.; Lima, C.; Martinelli, E. 2012. Fracture behaviour of concrete beams reinforced with mixed long/short steel fibres, Construction and Building Materials 37: 832-840. http://dx.doi.org/10.1016/j.conbuildmat.2012.07.060

Chern, J.-C.; Young, C.-H. 1989. Compressive creep and shrinkage of steel fibre reinforced concrete, International Journal of Cement Composites and Lightweight Concrete 11(4): 205-214. http://dx.doi.org/10.1016/0262-5075(89)90100-0

ENV 1992-1-1:2004 - Eurocode 2. Design of concrete structures, Part 1-1: General rules and rules for buildings. CEN, Brussels. 225 p. 
Ezeldin, A. S.; Shiah, T. W. 1995. Analytical immediate and long-term deflections of fibre-reinforced concrete beams, Journal of Structural Engineering 121(4): 727738.

http://dx.doi.org/10.1061/(ASCE)0733-9445(1995)121: $4(727)$

Gorzelańczyk, T.; Hola, T. 2011. Pore structure of selfcompacting concretes made using different superplasticizers, Archives of Civil and Mechanical Engineering 11(3): 611-621.

http://dx.doi.org/10.1016/S1644-9665(12)60104-6

Gribniak, V.; Kaklauskas, G.; Bacinskas, D. 2008. Shrinkage in reinforced concrete structures: a computational aspect, Journal of Civil Engineering and Management 14(1): 49-60.

http://dx.doi.org/10.3846/1392-3730.2008.14.49-60

Gruszczyński, M.; Podgórska, M. 2004. Ekonometria [Econometrcs]. Warsaw: Oficyna Wydawnicza Szkoly Glównej Handlowej. 430 p. (in Polish).

Grzybowski, M.; Shah, S. P. 1990. Shrinkage cracking in fibre reinforced concrete, ACI Materials Journal 87(2): $138-148$.

Hassan, A. M. T.; Jones, S. W.; Mahmud, G. H. 2012. Experimental test methods to determine the uniaxial tensile and compressive behaviour of ultra high performance fibre reinforced concrete (UHPFRC), Construction and Building Materials 37: 874-882. http://dx.doi.org/10.1016/j.conbuildmat.2012.04.030

Holschemacher, K.; Mueller, T.; Ribakov, Y. 2010. Effect of steel fibres on mechanical properties of high-strength concrete, Materials \& Design 31(5): 2604-2615. http://dx.doi.org/10.1016/j.matdes.2009.11.025

Kockal, N. U.; Turker, F. 2008. Drying shrinkage and strength gain of concretes with different cement and chemical admixture types, in Proc. of the 8th International Conference on Creep, Shrinkage and Durability of Concrete and Concrete Structures, 30 September-2 October, 2008, Ise-Shima, Japan, vol. 1: 249-255.

Luccioni, B.; Ruano, G.; Isla, F.; Zerbino, R.; Giaccio, G. 2012. A simple approach to model SFRC, Construction and Building Materials 37: 111-124. http://dx.doi.org/10.1016/j.conbuildmat.2012.07.027

Mihashi, H.; Maekawa, K.; Ishida, T.; Asamato, S.; Maruyama, I. 2008. Multi-scale modelling to link observed behaviour, characterization and analysis, in Proc. of the 8th International Conference on Creep, Shrinkage and Durability of Concrete and Concrete
Structures, 30 September-2 October 2008, Ise-Shima, Japan, vol. 1: 117-143.

Min, K. H.; Kwon, K. Y.; Kim, Y.; Yang, J. M.; Yoon, Y. S. 2008. An experimental study on time-dependent behaviours of early-aged concrete in various curing environments, in Proc. of the 8th International Conference on Creep, Shrinkage and Durability of Concrete and Concrete Structures, 30 September-2 October, 2008, Ise-Shima, Japan, vol. 1: 387-393.

RILEM. 1983. CPC 12 Measurement of deformation under compressive load, Matériaux et Construction 16(1): $43-48$.

Shah, A. A.; Ribakov, Y. 2011. Recent trends in steel fibered high-strength concrete, Materials \& Design 32(8-9): 4122-4151. http://dx.doi.org/10.1016/j.matdes.2011.03.030

Swamy, R. N.; Mangat, P. S. 1974. A theory for the flexural strength of steel fibre reinforced concrete, Cement and Concrete Research 4(2): 313-325. http://dx.doi.org/10.1016/0008-8846(74)90142-2

Szechiński, M. 2000. Long-term deflections of reinforced concrete beams under load. Wroclaw: Wroclaw University of Technology Publishing House. 244 p. (in Polish).

Velasco, R. V.; Toledo Filho, R. D.; Fairbairn, E. M. R.; Silvoso, M. M. 2008. Basic creep of steel fibres reinforced composites, in Proc. of the 8th International Conference on Creep, Shrinkage and Durability of Concrete and Concrete Structures, 30 September-2 October, 2008, Ise-Shima, Japan, vol. 1: 735-739.

Voo, Y. L.; Foster, S. J. 2010. Characteristics of ultra-high performance 'ductile' concrete and its impact on sustainable construction, The IES Journal Part A: Civil \& Structural Engineering 3(3): 168-187. http://dx.doi.org/10.1080/19373260.2010.492588

Watanabe, Y.; Ohura, T.; Nishio, H.; Tezuka, M. 2008. Practical prediction of creep, shrinkage and durability of concrete in Japan, in Proc. of the 8th International Conference on Creep, Shrinkage and durability of Concrete and Concrete Structures, 30 September-2 October 2008, Ise-Shima, Japan, vol. 1: 529-539.

Yazıcı, S.; İnan, G.; Tabak, V. 2007. Effect of aspect ratio and volume fraction of steel fibre on the mechanical properties of SFRC, Construction and Building Materials 21(6): 1250-1253.

http://dx.doi.org/10.1016/j.conbuildmat.2006.05.025

Czesław BYWALSKI. PhD, Senior Lecturer at Division of Concrete Structures of Institute of Building Engineering of Wroclaw University of Technology. The main research fields are: experimental and theoretical studies on reinforced concrete, steel fibre reinforced concrete, pre-stressed tanks for bulk solids and liquids and numerical modelling of concrete structures.

Mieczysław KAMIŃSKI. Professor of Civil Engineering. Head of Division of Concrete Structures of Institute of Building Engineering of Wroclaw University of Technology. The main research interests are: experimental and theoretical studies on reinforced concrete and pre-stressed tanks for bulk solids and liquids, cooling towers, limit states of reinforced and pre-stressed concrete beams and inspection of real industrial structures. 